\title{
Cytogenetic Studies in the Genus Narcissus L. VII. Karyotype and nucleolar condition in some N. pseudonarcissus L. cultivars
}

\author{
J. L. Karihaloo and A. K. Koul \\ Department of Biosciences, University of Jammu, Jammu 180001 , India
}

Accepted October 3, 1988

$N$. pseudonarcissus, popularly known as trumpet daffodil, is one of the most widely grown species of Narcissus. The plants are $30-50 \mathrm{~cm}$ tall with flat, glaucous, somewhat channelled leaves and solitary, drooping or horizontal flowers having trumpet shaped corona equalling or exceeding the length of perianth. Within these broad limits considerable variation in size and colour of flowers is found in the wild and cultivates varieties (Meyer 1966). Chromosome numbers of this species are in multiples of 7; eulpoids ranging from diploid to hexaploid and some aneuploid numbers have been reported (see e.g. Pugsley 1933, Fernandes and Fernandes 1946, Janaki Ammal and Wyllie 1949, Wylie 1952, Fernandes 1968 and Fernandes and de Almeida 1971). Cytological studies made by Sato (1938), Kurita (1955a, b) and Fernandes (1968) provide conflicting opinions about the morphology of the basic karyotype and the extent of genomic heteromorphicity in polypolid taxa. There is also disagereement among the above authors over the number and morphology of nucleolar chromsomes. Present studies on karyotype and interphase nucleoli of 5 cultivars of diverse pedigrees were carried out with a view to establish the extent of karyotypic variation.

\section{Materials and methods}

Bulbs of 'Telamonius Plenus' ( 2 collections), 'Golden Spur' (1 collection), 'Emperor' (6 collections), 'Empress' ( 1 collection), and 'Beersheba' ( 1 collection) were collected from private gardens, parks and nurseries in Kashmir. For chromosome studies from root tips, prefixing and squashing schedule described earlier (Karihaloo and Koul 1985) was followed. Terminology of Battaglia (1955) has been used for chromosome classification. Karyotypic comparisons have been made on the basis of chromosome arm ratio and relative length value, the latter representing the percent ratio of total length of a homologous set to the total chromatin length. Nucleolar studies were made from root tips following the procedure of Rattenbury (1952).

\section{Observations}

\section{Karyotype}

Chromosome numbers of the 5 cultivars were in multiples of base number 7 (Figs. 1-8). Of the 2 collections of 'Telamonius Plenus', one turned out to be a diploid $(2 n=14)$ (Fig. 1) and the other a tetraploid $(2 \mathrm{n}=28)$ (Fig. 2). Ranging between $11.1 \mu \mathrm{m}$ and $5.2 \mu \mathrm{m}$, the chromosomes of the diploid clone could be grouped into 7 homomorphic pairs (Fig. 9), 6 long $\left(\mathrm{L}_{1}-\mathrm{L}_{\mathrm{k}}\right)$ and 1 short $(\mathrm{S})$. Five long pairs were submetacentric and the sixth was acrocentric (Table 1). Among the submetacentric pairs $\mathrm{L}_{3}$ was approaching acrocentric while $\mathrm{L}_{4}$ and $\mathrm{L}_{5}$

${ }^{1}$ Present address: NFPTCR, National Bureau of Plant Genetic Resources, Pusa Campus, New Delhi110012, India. 
were approaching metacentric. The small pair was submetacentric and had a satellite on the short arm of each chromosome.

'Golden Spur', 'Emperor' and 'Empress' were triploid with 21 chromosomes (Figs. 3-6). 'Empress' had in addition 1 B-chromosome. This chromosome was similar in morphology to the short chromosome but was distinctly smaller (Figs. 6, 12). It was euchromatic and re-

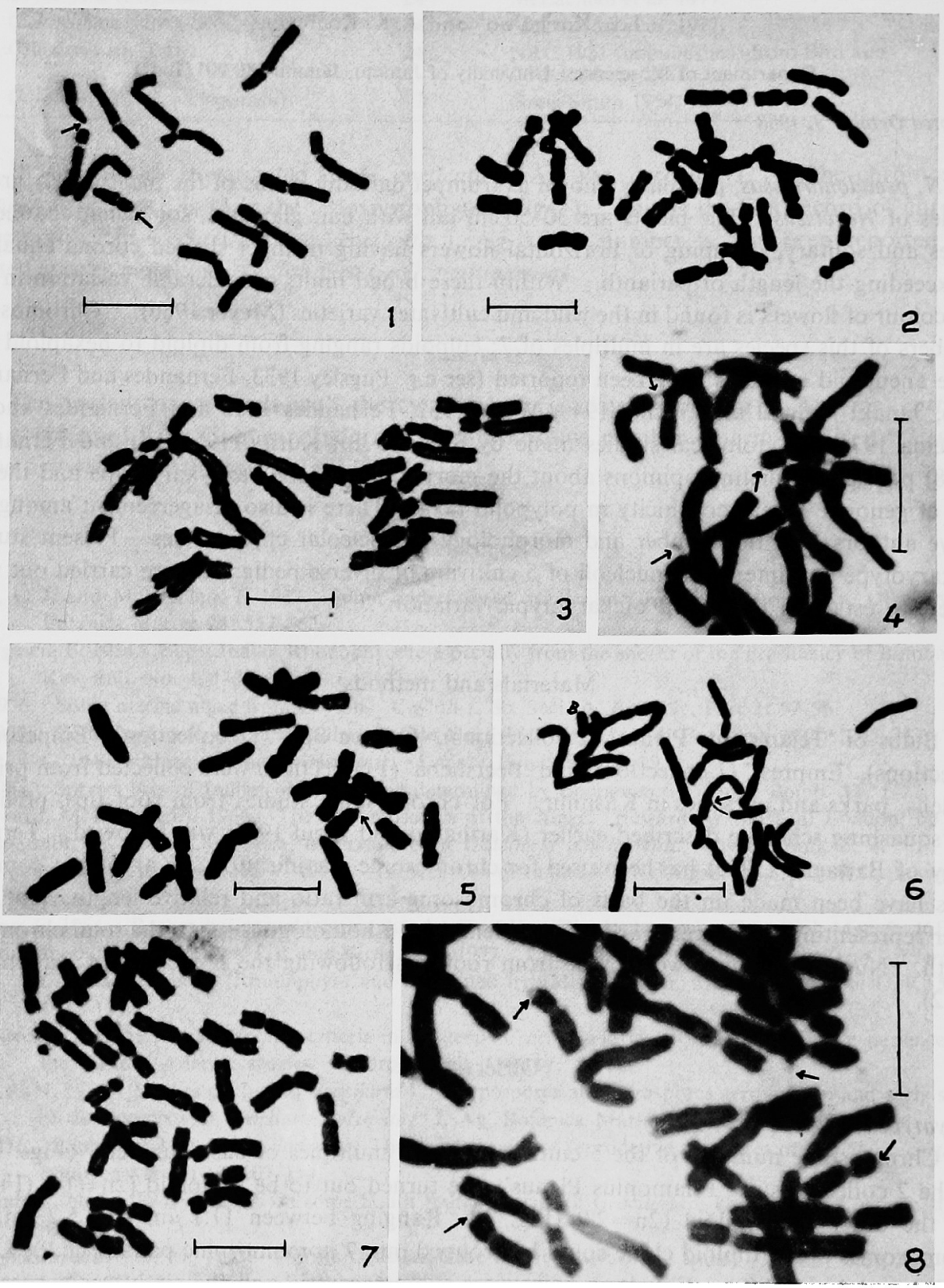

Figs. 1-8. Somatic chromosomes in N. pseudonarcissus cultivars. 1 and 2, diploid (Fig. 1) and tetraploid (Fig. 2) cytotypes in 'Telamonius Plenus'. 3 and 4, 'Golden Spur'. 4, shows 3 SATchromosomes. 5, 'Emperor'. 6, 'Empress'. 7 and 8, 'Beersheba'. 8, shows 4 SAT-chromosomes. SAT-chrornosomes are arrow marked. Note the B-chromosome in Fig. 6. Scale $10 \mu \mathrm{m}$. 
presented uniformly in all the cells scored.

Chromosomes in the 3 triploid cultivars, 'Golden Spur', 'Emperor', and 'Empress' could be arranged into 7 , mostly homomorphic triplets (Figs. 10-12). The karyotypes were broadly similar to that of 'Telamonius Plenus'; differences with the latter being observed in the $\mathrm{L}_{3}$ chromosome of 'Golden Spur', which was acrocentric and in the $\mathrm{L}_{6}$ of 'Emperor' which was submetacentric (Table 1). Triplet $\mathrm{L}_{2}$ of 'Golden Spur', was heteromorphic, one chromosome having distinctly shorter long arm than the other two.

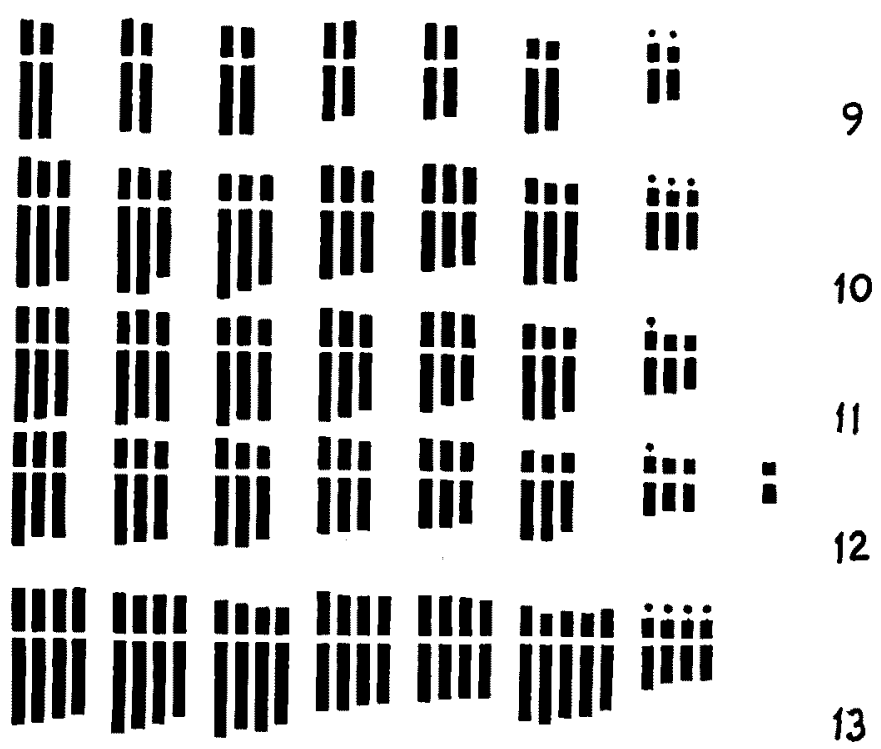

Figs. 9-13. Idiograms. 9, diploid 'Telamonius Plenus'. 10, 'Golden Spur'. 11, 'Emperor'. 12, 'Empress'. 13, 'Beersheba'.

Table 1. Relative length value (upper figures) and arm ratio (Lower figures) of chromosomes in the karyotypes of $5 \mathrm{~N}$. pscudonarcissus cultivars

\begin{tabular}{crrrrrrrr}
\hline \multirow{2}{*}{ Cultivar } & \multicolumn{7}{c}{ Chromosome number } \\
\cline { 2 - 9 } & \multicolumn{1}{c}{$\mathrm{L}_{1}$} & \multicolumn{1}{c}{$\mathrm{L}_{2}$} & \multicolumn{1}{c}{$\mathrm{L}_{3}$} & \multicolumn{1}{c}{$\mathrm{L}_{4}$} & \multicolumn{1}{c}{$\mathrm{L}_{5}$} & \multicolumn{1}{c}{$\mathrm{L}_{\text {8 }}$} & \multicolumn{1}{c}{$\mathrm{S}$} & B-chr. \\
\hline 'Telamonius & 17.60 & 16.65 & 16.18 & 14.35 & 13.72 & 13.32 & 8.17 & - \\
Plenus' & 2.36 & 1.97 & 2.36 & 1.45 & 1.49 & 3.31 & 1.45 & \\
'Golden & 17.43 & 16.59 & 15.11 & 14.96 & 14.07 & 13.58 & 8.25 & - \\
Spur' & 2.11 & 2.59 & 3.29 & 1.91 & 1.52 & 3.42 & 1.79 & - \\
'Emperor' & 16.90 & 16.50 & 15.68 & 15.68 & 13.85 & 13.03 & 8.35 & - \\
& 1.96 & 2.23 & 2.72 & 1.82 & 1.49 & 2.84 & 1.97 & \\
'Empress' & 17.20 & 16.00 & 15.89 & 14.62 & 13.42 & 13.36 & 7.77 & 1.73 \\
& 2.02 & 2.53 & 2.74 & 1.83 & 1.56 & 3.19 & 2.21 & 2.00 \\
'Beersheba' & 16.22 & 16.22 & 15.93 & 13.87 & 13.04 & 16.72 & 7.30 & - \\
& 1.92 & 2.20 & 2.71 & 1.59 & 1.37 & 2.78 & 2.62 & \\
\hline
\end{tabular}

The number of satellited chromosomes was also found to vary among the 3 cultivars, 'Golden Spur', 'Emperor' and 'Empress'. In 'Golden Spur' all the 3 short chromosomes were satellited (Fig. 4). In 'Emperor' and 'Empress', on the other hand, only one chromsome was satellited (Figs. 5, 6). This feature was common to all the 6 collections of 'Emperor' that were karyotyped. 
The present clone of 'Beersheba' turned out to be hypertertraploid (Fig. 7) with 29 chromosomes. These could be grouped into 7 homomorphic quadruplets and an additional chromosome which matched with the $\mathrm{L}_{\theta}$ group (Fig. 13). As expected, the relative length value of $\mathrm{L}_{\odot}$ set was prominently higher in 'Beersheba' than in the other cultivars. Except for this difference its karyotype was similar to that of the other 4 cultivars. In having both the $\mathrm{L}_{3}$ and $\mathrm{L}_{8}$ chromosomes with submedian centromeres this similarity was closer with 'Emperor'. All the 4 short chromosomes of this cultivar were satellited (Fig. 8).

Nucleoli :

Nucleolar studies were made in 4 cultivars (Table 2). The number of nucleoli per nucleus varied between 1 and the maximum, the latter being constant for the cultivar. Diploid clone of 'Telamonius Plenus' and 'Golden Spur' had a maximum of 2 and 3 nucleoli per nucleus respectively. All the nucleoli of a nucleus in these 2 cultivars were more or less equal in size
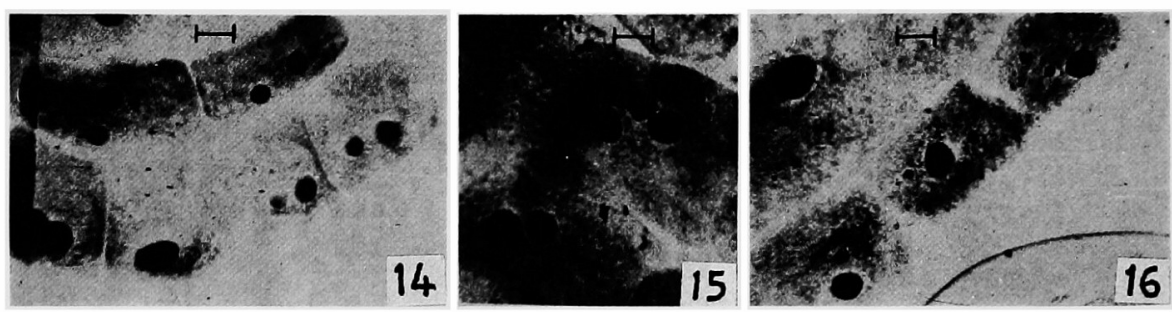

Figs. 14-16. Nucleoli in interphase nuclei. 14, diploid 'Telamonius Plenus'. 15, 'Golden Spur'. 16, 'Emperor'. Scale $10 \mu \mathrm{m}$.

Table 2. Nucleolar condition in 4 cvs. of $N$. pseudonarcissus

\begin{tabular}{|c|c|c|c|c|c|c|c|}
\hline \multirow[t]{2}{*}{ Cultivar } & \multicolumn{4}{|c|}{$\begin{array}{l}\% \text { frequency of cells } \\
\text { with indicated number } \\
\text { of nucleoli }\end{array}$} & \multirow{2}{*}{$\begin{array}{l}\text { Mean } \\
\text { nucleoli } \\
\text { per nucl- } \\
\text { eus }\end{array}$} & \multirow{2}{*}{$\begin{array}{l}\text { Total } \\
\text { cells } \\
\text { scored }\end{array}$} & \multirow{2}{*}{$\begin{array}{l}\text { Mean surface } \\
\text { area of } \\
\text { nucleoli } \\
\left(\mu \mathrm{m}^{2}\right)\end{array}$} \\
\hline & 1 & 2 & 3 & 4 & & & \\
\hline $\begin{array}{l}\text { 'Telamonius } \\
\text { Plenus' }\end{array}$ & 63.5 & 36.5 & - & - & 1.73 & 1579 & 137.1 \\
\hline $\begin{array}{l}\text { 'Golden } \\
\text { Spur' }\end{array}$ & 34.6 & 49.1 & 16.3 & - & 1.82 & 1565 & 163.8 \\
\hline 'Emperor' & 67.5 & 28.0 & 4.5 & - & 1.37 & 1339 & 101.2 \\
\hline 'Empress' & 79.0 & 166 & 4.2 & 0.2 & 126 & 1397 & 122.0 \\
\hline
\end{tabular}

(Figs. 14, 15). 'Emperor' and 'Empress' had 3 and 4 nucleoli respectively. However, only one of these was of normal size, the others being much smaller and much less frequent than those of 'Telamonius Plenus' or 'Golden Spur' (Fig. 16, Table 2). As a result the nucleolar frequency as also its size in the 2 cultivars 'Empreor' and 'Emperss', was lower than that of 'Golden Spur'.

\section{Discussion}

Chromosome numbers recorded in the 5 presently investigated cultivars are given in Table 3. 'Telamonius Plenus' has been recorded earlier as a diploid and a hypotetraploid, while the 2 clones in the present collection were diploid and tetraploid. 'Emperor', as reported by all the earlier workers, was found to be a triploid. The additional chromosome of 'Empress' was reported as a normal A-chromosome by $\operatorname{Nagao}(1929,1933)$ who accordingly put the 2 n num- 
ber at 22. Wylie (1952) followed by Brandham and Kirton (1987), however, regarded it as a B-chromosome probably because of its distinctly smaller size than the A-chromosomes. For the same reason the present authors also prefer to call it a B-chromosome though in the absence of any information on its pairing behaviour such a designation must remain arbitary. Three different chromosome numbers have been reported in 'Golden Spur'; the present count of $2 n=21$ agrees with that of de Mol (1922). Janaki Ammal and Wyllie (1949) and Brandham and Kirton (1987) recorded 'Beersheba' as a tetraploid while the present studies revealed the presence of a hypertriploid clone in this cultivar. The additional chromosome matches with the sixth chromosome of haploid complement.

Details of the chromosome morphology of $N$. pseudonarcissus have been provided by Sato (1938), Sikka (1940), Fernandes and Fernandes (1946), Kurita (1955a, b) and Fernandes (1968). The present observations agree with that of Kurita (1955a, b) and Fernandes (1968) who have reported a basic uniformity of karyotypes among different varieties and cultivars of the species. Both the authors agree that the haploid karyotype is comprised of 6 long to medium and 1 short chromosomes. Kurita (1955a, b) recorded 3 long chromosomes as submetacentric and the rest as acrocentric. Fernandes (1968) described all the chromosomes as submetacentric. However, 2 of the long type were approaching acrocentric and the other 2 metacentric. The

Table 3. Chromosome counts reported in the $5 \mathrm{~N}$. pseudonarcissus cultivars

\begin{tabular}{|c|c|c|}
\hline Cultivar & Present count & Earlier count \\
\hline 'Telamonius & 14,28 & De Mol 1922 \\
\hline Plenus’ & & Fernandes and de Almeida 1971 \\
\hline 'Emperor' & 21 & $\begin{array}{l}21 \text { Nagao 1933, Sikka 1940, Fernandes and Fernandes 1946, } \\
\text { Kurita 1955b, Barndham and Kirton } 1987\end{array}$ \\
\hline \multirow[t]{2}{*}{ 'Empress' } & $21+1 \mathrm{~B}$ & 22 Nagao 1929,1933 \\
\hline & & $21+1$ B Wylie 1952, Brandham and Kirton 1987 \\
\hline \multirow[t]{3}{*}{ 'Golden Spur' } & 21 & $\begin{array}{l}14 \text { Janaki Ammal and Wyllie 1949, Brandham and Kirton } \\
1987\end{array}$ \\
\hline & & 21 de Mol 1922 \\
\hline & & Nagao 1929 \\
\hline 'Beersheba' & 29 & 28 Janaki Ammal and Wyllie 1949, Brandham and Kirton \\
\hline
\end{tabular}

present observations match those of Fernandes (1968) more closely. Thus the karyotypes of the 5 cultivars reveal that the centromeric position in 2 chromosomes, $L_{3}$ and $L_{6}$, ranges between submedian and subterminal while all the rest have submedian centromeres. Among the latter group, $\mathrm{L}_{4}$ and $\mathrm{L}_{3}$ t $\in$ nd towards metacentric.

While there is a broad similarity among the karyotypes of the 5 cultivars studied presently, some differences, nevertheless do occur. 'Emperor' and 'Beersheba' bear quite similar karyotypes, both having all the chromosomes submetacentric. 'Telamonius Plenus' and 'Empress' have one chromosome, $\mathrm{L}_{6}$, acrocentric while 'Golden Spur' has two, $\mathbf{L}_{3}$ and $\mathbf{L}_{6}$, clearly acrocentric chromosomes.

Kurita (1955b) reported close similarity of constituent genomes in the karyotypes of 4 triploid and tetraploid $N$. pseudonarcissus cultivars. The chromosomes could be arranged into 7 homomorphic sets of 3 or 4 chromosomes and accordingly cultivars 'Emperor', 'King Alfred', 'Fortune' and 'Golden Harvest' were designated as autoploid. Earlier studies made by Nagao (1933) on the meiosis of 'Emperor' and 'King Alfred' showed high frequency of trivalent and quadrivalent configurations respectively, again indicating the autoploid nature of the cultivars. Sato (1938) and Sikka (1940), however, presented a contrary opinion. In a diploid cytotype of $N$. pseudonarcissus, Sato (1938) recorded one medium metacentric which 
did not match with any other chromsome of the complement. In hypertriploid 'Victoria' ( $2 \mathbf{n}=$ 22) and tetraploid 'King Alfred', Sikka (1940) could not group the chromosomes into matching triplets and quadruplets respectively and suggested the cultivars to be alloploid. The present studies reveal that the constituent genomes in all the 5 diploid and tetraploid cultivars bear close morphological similarity so that most of the chromsomes group into homomorphic sets. Clear heteromorphicity was evident only in $\mathrm{L}_{2}$ triplet of 'Golden Spur'.

The number and morphology of SAT-chromsomes is also a point of disagreement among various studies. Fernandes and Fernandes (1946) and Kurita (1955a, b) reported the satellite to be located on the short arm of small chromosome, the haploid set thus having one SATchromosome. Sikka (1940), however, recorded 3 different types of SAT-chromosomes in 'Victoria' and 'King Alfred': i) long chromosomes with satellite on long arm, ii) short chromosome with satellite on long arm and, iii) short chromosome with satellite on short arm. The present observations could confirm the presence of satellite only on the short arm of the short chromosome. That no other chromosome is satellited is evident from the nucleolar studies in cultivars 'Telamonius Plenus' and 'Golden Spur' where the maximum mumber of nucleoli equals the number of observed SAT-chromosomes.

The present studies reveal that in triploids 'Emperor' and 'Empress' in addition to one normal sized nucleolus, formed by the nucleolar organizing region (NOR) of the single SATchromosome, 2 and 3 very small nucleoli respectively appear in the interphase nuclei. Obviously, the minute nucleoli are organized by the NORs of the rest of short chromosomes, these NORs being either too small or too inactive to be observable at mitotic metaphase. The presence of fourth nucleolus in 3x 'Empress' indicates that in addition to the 3 short chromosomes, the B-chromosome present in this cultivar also shows some nucleolar organizing activity. This may not be surprising in view of the fact that the B-chromosome is morphologically similar to the short chromosome and could have possibly originated from it.

Intraspecific variation in NORs, caused by their loss or inactivation, has been reported in a large number of plants (Bose 1957, Ames and Mitra 1970, Bougourd and Parker 1976, Langer and Koul 1983) including $N$. triandrus and $N$. reflexus (Fernandes 1935, 1936, 1937). Gates (1942) has suggested that through gradual diminution a satellite may get reduced until it loses its visibility and later the functioning potentiality. Reduction of NORs can also take place as a result of amphiplasty (Navashin 1934) or suppression of NOR of one taxon by that of the other in a hybrid. It is interesting to note that 'Emperor' and 'Empress' have a common pedigree, both having arisen from a cross of $4 \mathrm{x} N$. pseudonarcissus bicolour and a $2 \mathrm{x} N$. pseudonarcissus variety (Anon 1975). The 2 triploids have arisen most likely by the fusion of $2 \mathrm{x}$ gametes from tetraploid variety with $\mathrm{x}$ gamete from diploid variety. Partial suppression of the 2 NORs of the former by the single NOR of the latter could result in the nucleolar condition observed in 'Emperor' and 'Empress'.

\section{Summary}

Karyological studies were made in 5 cultivars of $N$. pseudonarcissus; 'Telamonius Plenus' $(2 \mathrm{n}=14,28)$, 'Golden Spur' $(2 \mathrm{n}=21)$, 'Emperor' $(2 \mathrm{n}=21)$, 'Empress' $(2 \mathrm{n}=21+1 \mathrm{~B})$ and 'Beersheba' $(2 n=29)$. The basic set of 7 chromsomes bears broad similarity among these cultivars. Of the 6 long elements, 4 are submetacentric while the other 2 range between submetacentric and acrocentric. The short chromosome is submetacentric and satellited. Except in 'Golden Spur', where one triplet is heteromorphic, all the cultivars have homomorphic karyotypes. Diploid 'Telamonius Plenus', 3x 'Golden Spur' and 4x 'Beersheba' have 2, 3 and 4 satellited chromosomes respectively, whereas 'Emperor' and 'Empress', both $3 \mathrm{x}$, have only one. The number of nucleoli at interphase matches with the number of SAT-chromosomes in 'Telamonius 
Plenus' and 'Golden Spur'. 'Emperor' and 'Empress', however, have 2 and 3 additional, though vary small, nucleoli respectively.

\section{Literature}

Ames, I. H. and Mitra, J. 1970. Another variation in the satellited chromsome of Haplopappus gracilis. J. Hered. 61 : 236-238.

Anonymous 1975. Daffodil Data Bank of the American Daffodil Society. Compiled by Tom D. Throckmorton, Des Moines, Iowa.

Battaglia, E. 1955. Chromosome morphology and terminology. Caryologia 8: 179-187.

Bose, S. 1957. Aberrations in the nucleolar chromosome of inbred rye II. Size variation in inbred lines and population plants. Hereditas 43: 621-643.

Bougourd, S. M. and Parker, J. S. 1976. Nucleolar-organizer polymorphism in natural populations of Allium schoenoprasum. Chromosoma 56: 301-307.

Brandham, P. E. and Kirton, P. R. 1987. The chromosomes of species, hybrids and cultivars of Narcissus L. (Amaryllidaceae). Kew Bull. 42: 65-102.

Fernandes, A. 1935. Les satellites chez Narcissus reflexus Bot. et. $N$. triandrus L. I. Les satellites des metaphase somatiques. Bol. Soc. Brot., Sér. 2 10: 249-275.

-1 1936. Les satellites chez les Narcisses II. Les satellites pendant la mitose. Bol. Soc. Brot., Sér. 2 11: 87-142.

-. 1937. Les satellites chez les Narcisses III. Le nature du filament. Bol. Soc. Brot., Sér. 2 12: 139-158.

- 1968. Improvement in the classification of the genus Narcissus L. Plant Life 24: 51-57.

— and de Almeida, M. T. 1971. Sur les nombres chromosomiques de quelques formes horticoles du genre Narcissus L. I. Bol. Soc. Brot., Sér. 245 : 227-252.

- and Fernandes, R. 1946. Sur la caryo-systématique du scus-genre Ajax Spach du genre Narcissus L. Acta Univ. Conimbrig.: 1-33.

Gates, R. R. 1942. Nucleoli and related nuclear structure. Bot. Rev. 8: $337-409$.

Janaki Ammal, E. K. and Wyllie, A. 1949. Chromosome numbers of cultivated narcissi. Daffodil and Tulip Year Book 15: 33-40.

Karihaloo, J. L. and Koul, A. K. 1985. Cytogenetic studies in the genus Narcissus L. V. Cytology of N.pseudonarcissus L. $\times N$. poeticus L. cultivar 'Whitewell'. Cytologia 50: 275-281.

Kurita, M. 1955a. Cytological studies in Narcissus II. The karyotype of 3 species with $2 n=14$ chromosomes. Mem. Ehime Univ., Sec. II (Sci.), Ser. B (Biol.) 2: 71-76.

Kurita, M. 1955b. Cytological studies in Nurcissus III. The karyotype of tri-, tetra- and aneuploid plants on the basic chromosome number 7. Mem. Ehime Univ., Sec. II (Sci.), Ser. B (Biol.) 2: 77-83.

Langer, A. and Koul, A. K. 1983. Studies on nucleolus and nucleolar chromosome in angiosperms VII. Nature of nucleolar chromosome polymorphism in Allium cepa var. viviparum (Metzg.) Alef. Cylologia 48: 323-332.

Meyer, F. G. 1966. Narcissus species and wild hybrids. The Amer. Hort. Mag. 45: 47-76.

de Mol, W.E. 1922. The disapperarance of the diploid and triploid magnicoronati narcissi from the large cultures and the appearance in their place of the tetraploid forms. Proc. Koninklijke Akad. van Wetenschappen te Amsterdam. 25: 1-5.

Nagao, S. 1929. Karyological studies of the narcissus plant I. Somatic chromosome numbers of some garden varieties and some meiotic phases of a triploid variety. Mem. Coll. Sci., Kyoto Imp. Univ., Ser. B 4: $175-198$.

-. 1933. Number and behaviour of chromosomes in the genus Narcissus. Mem. Coll. Sci., Kyoto Imp. Univ., Ser. B 8: 81-200.

Navashin, M. 1934. Chromosome alterations caused by hybridization and their bearing upon certain general genetic problems. Cytologia 5: 169-203.

Pugsley, H. W. 1933. A monograph of Narcissus, subgenus Ajax. J. Royal Hort. Soc. 58: 17-93.

Rattenbury, J. A. 1952. Specific staining of nucleolar substance with acetocarmine. Stain Tech. 27: 113-120.

Sato, D. 1938. Karyotype alterations and phylogeny IV. Karyotype in Amaryllidaceae with special reference to the SAT-chromosome. Cytologia 9: 203-242.

Sikka, S. M. 1940. Study of somatic chromosomes in Narcissus. Ann. Bot. n.s. 4: 427-463.

Wylie, A. P. 1952. The history of the garden narcissi. Heredity 6: 137-156. 